\title{
0 jogo das narrativas: encadeamentos narratológicos do game The Sims ${ }^{1}$
}

\section{Marcos Braga e Regina Helena Silva}

\section{Resumo}

Com a temática "Games e Narrativas", o trabalho percorre um caminho, ou melhor, um possível "encadeamento narratológico" que, de certa forma, pôde conceder aos jogadores do game The Sims, a possibilidade de se expressarem e abordarem 0 cotidiano através de diferentes formas narrativas. Nesse trajeto, o game, as possibilidades narrativas do site oficial de The Sims, e as publicações dos "diários" virtuais do game, que são escritos pelos próprios jogadores a partir do cibercotidiano de seus avatares. Tentamos perceber, ao logo da pesquisa, como os jogadores conseguem se expressar, experimentar novas formas de tensionar e se fazer presente no mundo, por meio de uma das diversas possibilidades digitais de narrativa.

\section{Palavras-chave:}

Comunicação e tecnologia. Narrativas. Jogos digitais. Entretenimento. The Sims.

\section{Marcos Braga I marcoselizio1@yahoo.com.br}

Mestre em Comunicação Social pela Universidade Federal de Minas Gerais (UFMG), com dissertação defendida na área de Games e Narrativas. Especialista em Comunicação: Imagens e Culturas Midiáticas (UFMG), Bacharel em Publicidade e Propaganda (PUC-MG) e professor do curso de Pós-graduação em Artes Digitais do Centro Universitário UNA.

\section{Regina Helena Silva | regina.helena@gmail.com}

Possui graduação em Ciências Sociais pela Universidade Federal de Minas Gerais (1980), graduação em História pela Universidade Federal de Minas Gerais (1982), mestrado em Ciência Política pela Universidade Federal de Minas Gerais (1991) e doutorado em História Social pela Universidade de São Paulo (1997). Atualmente é Professora Associada II da Universidade Federal de Minas Gerais e atua nos programas de pós-graduação em História e em Comunicação Social.

\section{Chaves de leitura do mundo}

Ao longo da história, o desenvolvimento da mídia e o surgimento das tecnologias da comunicação e informação (TCIs), de certa forma, influenciaram a maneira como o homem percebe e constrói o mundo à sua volta. A inauguração de novos dispositivos ${ }^{2}$, gêneros e tecnologias, que embarcam os mais variados entrecruzamentos de imagens e narrativas em todas as épocas, evocaram posturas diferenciadas dos indivíduos para inéditas possibilidades de intercâmbios sociais e simbólicos. 0s produtos midiáticos e seus aparatos tecnológicos não apenas constroem enunciados e representações, mas também uma série tensões que entram em constante choque com os saberes das instâncias interlocutoras, provocando por vezes novas posturas, atualizações, reivindicações e quadros interpretativos, passando a ser observados como "chaves de leituras" do mundo.

0 homem, por sua vez, é sujeito significante, questionador e demonstra admirável capacidade de se expressar frente aos diversos desafios de sua vida. Ele elabora, compreende e 
comunica, sendo que é através da linguagem que se faz manifesto no mundo, e é por meio das formatações peculiares das narrativas que apreende, interroga, tensiona e se faz compreender. A linguagem confere consciência ao ser humano, e pelo seu caráter iluminador, revela o ser íntimo, exterioriza o universo oculto, aprofunda e amplia o existir pessoal e social. Mas, novamente, será por meio das narrativas que teremos a possibilidade de formatação de algumas áreas da complexa dimensão da linguagem - seja ela verbal, física, emocional, lúdica, ética, técnica, individual ou coletiva. Posta em ação, nos embates do cotidiano, se alimenta e se atualiza nas interlocuções que afloram dos processos comunicativos.

No lastro dessa constante negociação narrativa, em cada época, a evolução das tecnologias da comunicação e da informação, em potência, não somente auxiliou os sujeitos a tensionar as simbologias cotidianas, mas também assinalou uma mudança no modo como os próprios indivíduos apreendem o mundo. De acordo com Gláucio Aranha (2006), historicamente, os esforços tecnológicos voltados aos processos de comunicação mediada revolucionaram os sistemas sociais e de transmissão de saberes, rompendo violentamente com as noções espaciais e temporais vigentes. Por exemplo, com a descoberta das técnicas fotográficas e do fonógrafo, o homem pode não somente comunicar entre longas distâncias, mas também apreender e manipular imagens e memórias. 0 rádio foi a mídia que melhor viabilizou a comunicação entre pontos distantes, acrescentando o poder de sua tradição oral (voz, sons, músicas, entre outras), coincidindo mais facilmente 0 tempo do acontecimento e o tempo de escuta, garantindo uma sensação de atualidade e co-temporalidade. A TV, além de sua competência audiovisual avançada, sua veiculação e acesso global, pode também ser considerada uma arena rica de discursos, um locus onde ecoam e ganham importância os diferentes atores e quadros da vida social. E, no último quarto do século XX, estamos ainda descobrindo que o computador e os games não se destinam apenas ao entretenimento, mas à comunicação, e todo um novo conjunto de responsabilidades que nos desafia.

Janet H. Murray (2003), ao se indagar sobre o futuro da narrativa no ciberespaço, percebe que os games, potencialmente, também podem se apresentar como um campo fértil de representações, trocas e produções simbólicas. Para a autora, o jogo é um tipo de narrativa que se assemelha muito ao universo da experiência

0 presente artigo é resultado da dissertação de Mestrado, defendida em dezembro de 2009, no Programa de Pós-Graduação em Comunicação Social da Universidade Federal de Minas Gerias.

"0 dispositivo é um componente do contrato de comunicação sem o qual não há interpretação possível das mensagens, da mesma forma que uma peça de teatro não faria muito sentido sem o seu dispositivo cênico. De maneira geral, ele compreende um ou vários tipos de materiais e se constitui como um suporte com o auxílio de uma certa tecnologia" (CHARAUDEAU, 2006, p. 105). 
cotidiana; ou, como assinalava Johan Huizinga (1971): a atividade lúdica está na origem da cultura do homem, sendo que a ideia de jogo é central nas civilizações. Assim, de acordo com 0 filósofo, em jogo temos a oportunidade de simular ou encenar nossa relação com o mundo, vencer as dificuldades, sobreviver às inevitáveis batalhas, redecorar nosso espaço, repensar nosso tempo e dominar as mais adversas situações. "Os jogos oferecem um treinamento seguro em áreas que possuem um valor prático real; eles constituem ensaios para vida" (MURRAY, 2003, p.142).

Tendo em vista essa fascinante experiência narrativa que os sujeitos percorrem pelo mundo e pelas mídias, em busca de entendimento e "chaves de leituras" sobre seu mundo, iremos falar neste trabalho sobre um encadeamento narrativo peculiar. Analisaremos a construção de um avatar em um jogo eletrônico - o game The Sims - que pretende simular algumas ações do cotidiano dos jogadores. Logo, no site oficial do jogo, ainda existe a possibilidade de construir novas narrativas, no formato de "diários virtuais", a partir (ou não) da trama desenvolvida no game. Nessa trajetória - do jogo para os diários - os sujeitos acabam encontrando outros jogadores, experimentando novos caminhos midiáticos, publicando produtos inéditos, lendo textos diversos e adquirindo novas experiências e repertórios. Mais de que um meio para o puro entretenimento, os jogos, e atualmente os games eletrônicos, permitem aos sujeitos experimentar, de maneira segura e com uma temporalidade peculiar, formas de narrar e assimilar a complexidade simbólica que perpassa pelo cotidiano que os cerca.

\section{Jogar, narrar, comunicar}

De maneira geral, temos a ideia de que narrar é apenas contar uma história, um fato ou um acontecimento. Mas o que deixamos de perceber no atropelo dos contos, mitos, "causos", estórias, acentos, sujeitos, verbos e frases que habitam a tecitura do texto é que ao narrar estamos também comunicando. A atividade narrativa, em suas diversas concepções e dimensões, figura-se como uma arena de saberes onde as práticas estão marcadas pela heterogeneidade das experiências e pela dinâmica dos elementos que compõem seu corpus. Narrar é senão uma maneira de comunicar, e, portanto, não podemos dividir e conformar de maneira arbitrária os lugares de "quem narra" e de "quem escuta" o texto. Ambos participam ativamente de uma produção que se entrelaça em uma malha tecida pela ação e pela experiência dos indivíduos. "Trata-se de uma relação travada à maneira de um pacto no qual a narrativa, ao ser instaurada a partir desse encontro, emerge e se manifesta, fortemente licerçada tanto no texto no qual estava contida em potência, quanto no interlocutor que a aciona e a faz acontecer" (COUTINHO, 2007). Como vimos, o texto está inserido em campo de tensionamentos, que o modifica, atualiza, organiza, extende, nega, e o qualifica em uma multiplicidade de quadros interpretativos. 
Pesquisar as narrativas, portanto, constitui uma perspectiva analítica que busca compreender não só a complexidade dos vínculos sociais, tal como encenados, performados, no mundo contemporâneo, como também as diferenças que essa forma peculiar de organização do mundo apresenta, implica, desdobra, aos sujeitos, à experiência, aos saberes, aos cotidianos (LEAL, 2006, p. 21).

É por meio das narrativas que os sujeitos tentam compreender e se impor no mundo como um agente ativo da dinâmica comunicacional. As narrativas produzidas e negociadas tanto "na mídia quanto nas ruas", mesmo munidas de seus equadramentos, edições, formatações e plataformas diversas, se apresentam como ferramentas que podem auxiliar os sujeitos a perceber, conhecer e negociar seu espaço no mundo. Desde as primeiras formas de produções imagéticas até as formas mais contemporâneas como o cinema, a TV, o vídeo, o computador e os games, as tecnologias da imagem fornecem elementos narrativos que, juntamente com fatores sócio-históricos e culturais, contribuem para a reafirmação, tensionamento, construção da subjetividade e da percepção do indivíduo acerca do cotidiano em que vive. Nessa busca incessante pelo conhecimento, de si e do mundo, os sujeitos se aventuram em jornais, revistas, sites, games e "diários virtuais", procurando pistas ou "chaves de leitura" que por ora tranduzem algumas linhas que desenham 0 complexo cotidiano.

Na modernidade, coube ao cinema, como meio de comunicação e "máquina de visão", desempenhar um importante papel nesse sentido. Para Walter Benjamim (1996), as técnicas de reprodução das imagens, bem como as diversas narrativas, lentes e recortes utilizados pelo cinema, surgiram como formas de exercitar a percepção de mundo dos sujeitos, bem como de trabalhar as produções de sentido presentes no cotidiano do homem moderno. 0 contato com 0 cinema submeteu 0 espectador às mudanças de lugares que a narrativa exige, proporcionando uma maneira de trabalhar os sentidos na dinâmica do tempo de quem 0 apreende. 0 grande poder de atração das imagens em movimento gerado pelos filmes aparece como um fator de transformação para o imaginário visual e simbólico do espectador, possibilitando, assim, novas atitudes do público, que passa a se apresentar como realizadores e atores, transformados pelo progresso técnico e estético dessa invenção. Benjamin vê o surgimento do cinema como uma espécie de escola do olhar e do sentir o mundo, que vem a auxiliar a percepção do tempo e dos espaços, que se apresentam na modernidade de modo descontínuo.

Hoje, temos os jogos midiatizados pelo digital, que, junto a outras mídias como os chats, fóruns, twitters, blogs, mobiles e outros, podem proporcionar um aprendizado de como lidar e se adaptar à lógica descontínua exigida pela contemporaneidade. Além disso, eles podem proporcionar àqueles que participam desse processo comunicativo a socialização em territórios virtuais; a criação e apropriação de 
novas simbologias; a troca de referências que podem modificar ou reafirmar perspectivas diversas; e, através de seus aparatos narrativos, um sem-número de representações e fantasias capazes de interferir no modo como 0 indivíduo desenvolve seus valores, crenças e sua percepção de mundo. Incluímos ainda neste viés o possível nascimento de uma nova compreensão de espaço/tempo e, até mesmo, de novas habilidades de como lidar com os dispositivos comunicacionais (os sujeitos, por exemplo, podem exigir informações cada vez mais rápidas, para consumir ou descartar, socializar, atualizar ou publicar sua opinião).

Dentro dessa lógica de análise, o objeto que escolhemos analisar como produto de estudo é 0 encadeamento narrativo que pode-se formar nas bases do game The Sims. 0 jogo foi criado por Will Wright e lançado nos anos 2000 após a série de jogos Sim City, do mesmo autor. 0 game funciona como um lúdico "simulador de cotidiano", que, através de certas regras, parâmetros e referências, disponibiliza um mundo virtual que pode ser vertiginosamente experimentado por seu jogadores. A dinâmica construída no game se materializa na simulação de um "cibercotidiano" em que podem ser encenadas algumas ações corriqueiras do dia-a-dia dos sujeitos como trabalhar, pagar contas, namorar, dormir e comprar. Tecnicamente, não há maneiras de se vencer o jogo; o objetivo é evoluir, superar desafios, alcançar desejos e aspirações. 0 jogador pode construir avatares, cenários, relações sociais, além de poder pausar, salvar e acelerar o tempo da ação. A ideia central do game é a de um teatro virtual, no qual podemos encenar e "treinar" ludicamente quadros de nossas vidas. Mesmo através da limitação dos dispositivos de um simulador, temos aí um produto narrativamente rico que ainda possibilita ao jogador a oportunidade de se tornar membro do site e da comunidade oficial do jogo, além de escrever e publicar histórias em seus diários online. Um encadeamento narrativo peculiar que, ao ser analisado de perto, concede pistas e/ou rastros sobre sujeitos, relações, experiências e mundos diversos.

Figura 1 - Imagens do jogo The Sims
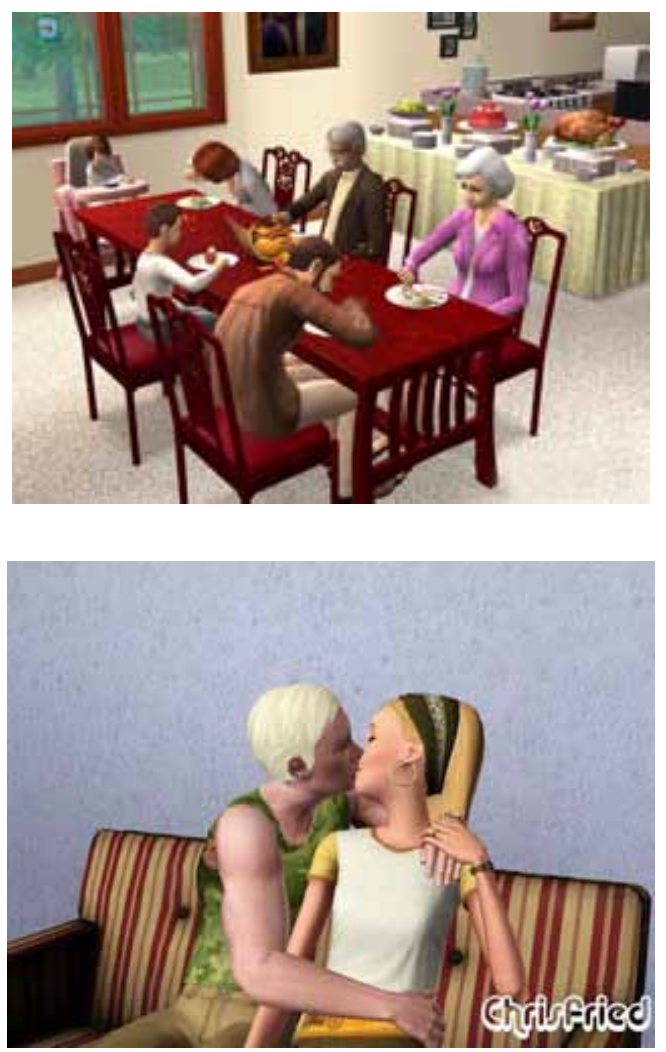
Em The Sims e em seus diários virtuais, escritos pelos próprios jogadores no site oficial do game, o cotidiano se faz presente na narrativa tecida pelos sons, imagens e pela ação dos avatares na tela. São os próprios sujeitos que tensionam, experimentam, criam possibilidades e treinam múltiplas formas de ver e sentir o mundo. Nesse lúdico exercício narratológico, os sujeitos, ao se fazerem de alguma forma presentes no ciberespaço, podem tatear pistas de seu papel no mundo, e se sentir motivados a buscar novas experiências. Veremos, a seguir, que o jogador, no game The Sims, nos diários virtuais e em outros ambientes, pode interagir, interpretar, participar, criar e transformar narrativas, cenários, máscaras e relações. Em um exercício lúdico de conhecimento de "si" e do mundo, nesses espaços, é capaz de negociar pontos de vista, fomentar futuros debates e, de certa forma, refletir e reforçar modelos de comportamento, visões do mundo. Pode, também, auxiliar, por meio das narrativas do jogo e dos diários, na construção, assimilação e compreensão das diversas formas de significações no ambiente contemporâneo. Quando um jogador joga The Sims, ele está brincando de ser criador e controlador de modelos virtuais de vida e narrativas.

\section{Encadeamentos narratológicos de The Sims}

Ao habitar ambientes digitais, o jogador pode ser encorajado a realizar 0 mesmo exercício que, de certa maneira, o homem faz com seu mundo atual, consigo próprio e com os outros ao seu redor. 0 personagem pode explorar todas as possibilidades do ambiente, e é através de sua ação e intervenção no ciberespaço que o mundo virtual ganha vida. Uma atividade organizante, de construção de um mundo comum através da ação e da interação, fundadora de novos posicionamentos e quadros de sentido. Os jogos e outras ferramentas narrativas digitais, como os diários de The Sims, podem levar os indivíduos, a partir de seus desejos e suas perspectivas culturais, a criar universos temporais e espaciais diversos, bem como elaborar e encarnar-se em um personagem, em uma narrativa ou em outra personalidade. Evoca leituras, interpretação, interferência, imaginação e uma atitude imersiva, ou seja, uma suspensão convencional do atual, para que a liberdade da simulação ou da representação se estabeleça.

Segundo Edmond Couchot (1993), tudo se passa então como se a simulação numérica levasse ao aparecimento de uma nova dimensão do real, não como uma cópia, nem como representação ou duplicação, mas como um análogo transformado e transmutado pelo cálculo binário. Análogo numérico do mundo, das coisas, das realidades naturais ou artificiais, análogo numérico dos próprios sujeitos de percepção, pensantes e ativos, de seu corpo, dos gestos, da escrita e do pensamento. Uma 
condição que permite, até certo ponto, uma previsão e "manipulação", no sentido de coautoria e maleabilidade, do mundo. Nesses jogos simulados, frente a outros selfs e ao ciberespaço, a narrativa se estabelece como um todo integrado que leva consigo múltiplos modos de comportamentos: a fala (escrita), os gestos, o visual, os espaços interindividuais, os múltiplos contextos sociais e culturais, entre outros. Nos jogos virtuais, assim como na vida ordinária, é impossível pensar a comunicação e as narrativas como uma unidade monofônica; ela deve ser pensada como um complexo global, fluido e multifacetado.

Neste artigo, estamos indo um pouco além das narrativas que são produzidas pelo jogo e no jogo. Estamos incluindo também neste viés - encadeamento narratológico - os "diários" que são escritos e publicados pelos jogadores no site oficial do game The Sims. Os usuários/jogadores, que estão cadastrados no site oficial do game, podem escrever novas estórias publicando textos sobre 0 cotidiano de seus avatares, e/ou explorar uma multiplicidade de perspectivas que por vezes fogem das barreiras impostas pela narrativa do próprio The Sims. Por exemplo: em jogo não podemos quebrar objetos, ter super-poderes ou assassinar um outro personagem. Nos diários, como a narrativa obedece a estrutura da linguagem escrita, as barreiras virtuais ganham outras dimensões.
Agora, o jogador, antes limitado pelo software e pelas regras do jogo, se expressa no texto através de uma pluralidade de variáveis que só depende do caminho que sua imaginação possa levar. Nessa trajetória, o jogador toma para si o controle da própria estória, deixando de ser apenas um intérprete de um mundo simulado, passando a ser o diretor de seu próprio mundo imaginado. Esses "diários", como são denominados no site, se apresentam como um novo campo narrativo e comunicacional que surge do desejo dos jogadores de The Sims de explorar e especular, sozinhos ou em conjunto, outras possibilidades textuais. Um pouco diferente da proposta dos "diários pessoais virtuais" que hoje conhecemos como "blogs", os diários de The Sims possuem uma proposta inicial diferente. Em primeira instância, foram elaborados para contar, em uma plataforma escrita, as experiências virtuais que os personagens viveram quando em jogo. Mas, assim como os blogs - que se distanciaram da proposta de serem equivalentes aos antigos diários pessoais-, os diários virtuais de The Sims ganharam potencialmente um novo uso. As particularidades desse novo recurso narrativo não se limitaram somente na produção de um relato a partir do cotidiano virtual de um avatar, mas também na possibilidade de testar e explorar novas possibilidades de texto e enredos, publicá-las e atualizá-las, a partir - ou não - do encontro com os possíveis leitores. 
Figura 2 - Um diário de The Sims: a história de "Bernardo \& Bianca" escrito pela autora "Mynna"

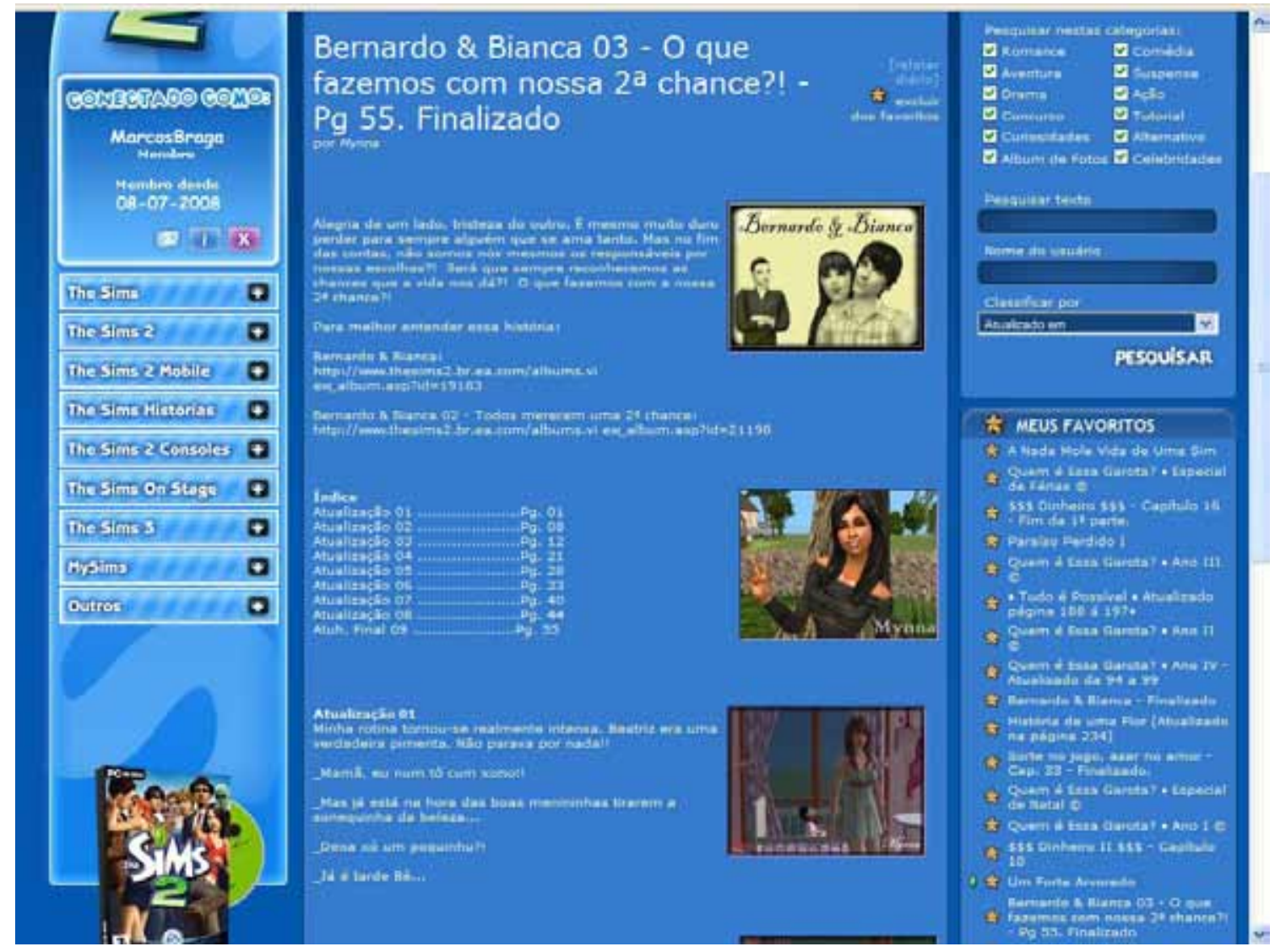

Esses textos estão ligados diretamente à dinâmica do jogo, e também possuem a narrativa fortemente marcada por um semnúmero de experiências, contextos, saberes e lugares de fala que os autores utilizam ao escrever as narrativas. No site oficial, ao serem postados, esses diários ganham um certo campo de visibilidade, além de serem lidos e comentados por outros jogadores. No fórum do site, os autores e leitores ainda podem conversar a respeito da narrativa, tendo a possibilidade de gerar, a partir desse encontro, novas atualizações, enredos e encaminhamentos para a trama escrita. É no jogar, escrever e interagir que os sujeitos acabam por experimentar ludicamente algumas formas de comentar, argumentar, explicar e relatar algumas perpectivas sobre 0 mundo. Neste caso, em busca de lugares e "maneiras de se encontrar", foi preciso criar um avatar em um game de simulação, escrever um diário sobre o cotidiano virtual do personagem, interagir com alguns leitores sobre as narrativas sugeridas, e futuramente habitar outros lugares em busca de novas narrativas que digam algo sobre si e sobre o mundo. 
Como vimos, o jogo The Sims se coloca não somente como um game que, separado do curso do cotidiano se qualifica como um simples passatempo para jogadores desinteressados. 0 jogo ultrapassa sua plataforma que é originalmente offline e migra para outras instâncias, sejam elas online ou mobile (celular), sites oficiais ou extra-oficiais, que acabam por construír e fomentar um rico encadeamento narratológico e uma possível rede de relações entre os jogadores mais interessados. Veremos como o game se coloca como uma interessante malha narrativa que é construída diariamente entre os jogadores que se cadastram no site ofcial de game, leem, escrevem e compartilham diários, participam de fóruns, criam laços, ganham visibilidade nos grupos, se atualizam e produzem informações sobre o jogo.

Para entendermos melhor esta rede de interações, foi elaborado um pequeno esquema de vetores para facilitar a visualização das relações jogo/ site e autores/leitores que podem ocorrer em The Sims. Através desta pequeno percurso já podemos perceber um caminho diferente que sujeitos podem se permitir para a produção de narrativas.

Figura 3 - Gráfico dos ambientes narratológicos de The Sims

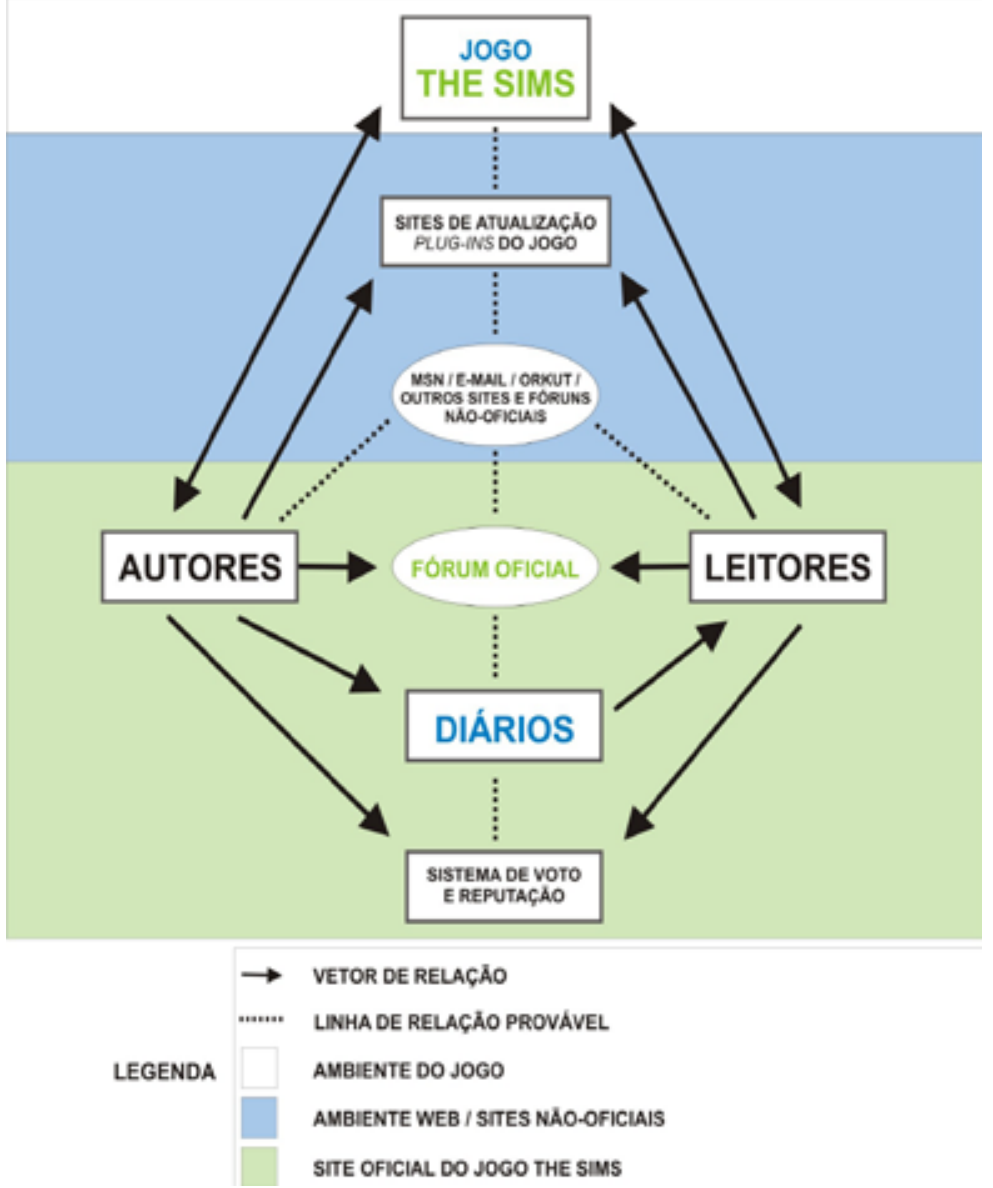


Como ilustrado na Figura 2, podemos notar que os jogadores podem transitar por três ambientes distintos: a plataforma do game, 0 site oficial e os ambientes considerados "nãooficiais". Nesse encadeamento narratológico que The Sims e seus diários podem proporcionar a seus jogadores, podemos pensar o seguinte fluxo: há uma proposta de narrativa, formatada e programada com a intenção de simular 0 cotidiano dos sujeitos. 0 convite para a participar desse cibercotidiano é feito de maneira lúdica, em formato de um game. 0s sujeitos; munidos de seus saberes, tempos, quadros de sentido, aspirações e angustias; se aventuram pelo game colocando em jogo suas habilidades e inquietações. É no cibercotidiano do jogo, que os players poderão negociar a todo momento, o enredo o qual desejará encenar. Para tanto, poderá acelerar e pausar o tempo da narrativa, salvar ou começar uma nova história, inserir novos personagens, investir em relacionamentos e vivenciar situações diversas. Todas essas situações virtuais podem guardar semelhança ao seu cotidiano atual ou pode se opor a ele em quase todas as ações desenvolvidas pelo avatar. Ao buscar se munir de mais ferramentas para compreender e aprimorar a narrativa que é negociada no ciberespaço, os sujeitos podem procurar percorrer outros ambientes que dizem mais a respeito daquela experiência virtual.

Nesta trajetória, acabam por encontrar o site oficial do jogo, e são convidados a se cadastrar e tornar-se membro do grupo de jogadores que fomentam a dinâmica do portal. Sem perceber, neste exercício, extendem a narrativa do game, procurando tutoriais, dicas, novas atualizações e outros jogadores para interagir e conversar a respeito de suas experiências. Ao navegar pelo site, 0 jogador encontra à sua disposição uma ferramenta de criação de diários virtuais, ou melhor, de construção de narrativas que dizem respeito ao cotidiano virtual de seu avatar. Ao tentar escrever um diário virtual, o jogador percebe que precisará voltar várias vezes para 0 ambiente de jogo, ora para lembrar de detalhes da estória, ora para fotografar as ações de seu personagem. 0 que acaba descobrindo é que a narrativa que criará nos diários virtuais do site não necessariamente precisa ter um caráter de diário, ou seja, contar passo-a-passo o cotidiano de seu avatar. A liberdade do texto escrito lhe permite elaborar narrativas tão diversas e destoantes quanto sua imaginação pode propor. Mais uma vez, além de estender novamente a ação narrativa que outrora se limitava às regras precedimentais do jogo, os sujeitos podem novamente agir em campo seguro para tentar, através de um exercício lúdico, descobrir algumas pistas sobre sua presença e seu lugar no cotidiano atual. Ao publicar os diários virtuais, dependendo do envolvimento do "autor" com o site e com fórum do portal, há a possibilidade de interagir com outros jogadores, o que pode proporcionar futuras atualizações no enredo das estórias publicadas. No fórum do site, autores e leitores podem se encontrar em espaços 
pré-definidos para conversar sobre os diários.

Nesse espaço, desde a simples postagem de uma sugestão, reclamação ou provocação dos leitores no enredo ou na habilidade de escrita do autor, podem surgir e se estreitar laços de interação que podem levar os sujeitos a outros ambientes de conversa (orkut, msn, e-mail, twitter, sites oficiosos, entre outros).

\section{Em The Sims, temos uma narrativa na qual} 0 agente é, ao mesmo tempo, externo e contralador das ações e encaminhamentos do texto, mas que interfere na própria trama da estória. 0 agente da narrativa define 0 tempo e o espaço da narrativa, edita as propriedades e atributos de cada personagem, toma decisões, elabora desafios para trama e encaminha os personagens para diferentes destinos. Internamente, tanto no jogo quanto nos diários virtuais, o jogador/autor/leitor pode fazer-se presente na narrativa quando vertiginosamente se projeta no mundo ficcional, ora na construção de um avatar, ora na construção de seu diário pessoal. Mas, para narrar sobre seu mundo, ele precisa estar engajado no cotidiano que 0 cerca, fazendo-se narrativamente presente frente ao "outro", entendendo e se fazendo entender, atualizando e construindo explicações e perpectivas, para que estas sejam úteis em futuras investidas e experiências.

Assim, mais do que uma narrativa - como observado por Janet Murray (2003) - que se conforma em fórmulas do tipo "bandido pega ladrão" ou "mocinho salva a princesa", em The Sims é possível pensar em dois fluxos narrativos. 0 primeiro se corforma nos embates que 0 jogador/autor possui com o próprio enredo. Ao jogar o game de simulação do cotidiano, ele produz uma série de ações narrativas, que por vezes são limitadas pelo software do jogo. Em busca de mais desafios e elementos que enriqueçam a narrativa, o jogador pode comprar e instalar expansões para o jogo, pacotes de atualizações e outros arquivos que, de alguma forma, fazem com que o texto se faça mais convincente para ele próprio. Ao cessar novamente suas possibilidades de ação dentro do software, a inquietação do enredo permanece. $\mathrm{E}$, ao perceber que existe uma possibilidade de continuar e/ou extrapolar sua narrativa em outro ambiente, o jogador que antes no enredo se apresentava como um simples cidadão de uma cidade virtual, agora ganha novas particulariedades que só a habilidade da escrita pode exprimir. 0 enredo fatalmente se atualiza e se extende nos diários virtuais de The Sims. Publicado em um ambiente construído por pessoas minimamente interessadas pelo jogo, uma nova narrativa pode ser foco de atenção e tensionamentos nos fóruns e outros ambientes de conversa. Mais uma vez, o enredo que timidamente começou como uma lúdica proposta simulativa, se torna uma publicação autoral em site oficial da produtora do game. 0 segundo fluxo narrativo é senão desenhado pelos próprios sujeitos, que jogam o jogo ou escrevem 
seus diários virtuais. Esse fluxo se desenha no caminho que os sujeitos percorrem ao jogar The Sims e acessar o site oficial do jogo; no exercício que se permitem ao aceitar a proposta do game e da produção de diários virtuais; na decisão da escrita e na publicação de seus textos no site da produtora; na disposição de se colocar no campo de visibilidade e de embates no fórum do site; na tentativa de buscar novas informações e formar vínculos; na busca por outros lugares de fala e de ação em ambientes diferenciados. Nessa caminhada incessante é que os sujeitos acabam descobrindo pistas sobre si próprios: o que pensam, o que fariam em determinadas situações, o que temem, o que desejam, em qual lugar se colocariam em determinados debates, $\mathrm{e}$ outras "chaves de leitura" que tentam posicionálo frente ao seu cotidiano.

Nesse caminho, The Sims possui características claras que, por vezes, podem potencializar (ou despotencializar) a atividade lúdica e a construção da narrativa. A potência narrativa da não-linearidade e a presença de obstáculos a serem superados é uma premissa importante para que uma atividade lúdica exerça fascínio e contribua para 0 entendimento e adaptação do indivíduo frente às exigências de uma sociedade pautada pelo excesso de estímulos visuais e de informações. Porém, mesmo que a interação permitida seja alta e por mais que o jogador possa criar personagens e histórias dentro do jogo, essa criação sempre será conduzida por regras e limites de interferência impostos pelo software, o que constitui uma certa despotencialização.

Mas acredito que as limitações impostas pelos dispositivos técnicos do game não castram de maneira totalizante a fruição, produção e interlocução social e simbólica realizada com e a partir do jogo.

A trajetória analítica deste artigo nos mostrou que, longe de ser uma resposta à latente angústia e sede dos indivíduos de conhecer 0 mundo, e consequentemente a si mesmos, 0 possível encadeamento narrativo encontrado em The Sims dá 0 aval a uma relevante oportunidade de expressão. Através do recurso da linguagem formatada em específicas combinações narrativas, é possível externar algumas inquietações presentes no imensurável universo interno dos indivíduos. E a cada nova oportunidade de relatar, comentar e dizer sobre o mundo, os sujeitos acabam procurando por outras e novas formas de narrar, em uma contínua busca por outras "ligas" do encadeamento narratológico. Na cadeia narrativa de The Sims, alguns encontraram a possibilidade de dividir com o "outro" estórias sobre as diversas perspectivas do cotidiano, e de vertiginosamente treinar, ensaiar ou somente jogar no ambiente simulativo do game, de maneira segura, uma série de ações que podem possuir um valor prático real para suas vidas. Porém, é vendo a produção, a ação e os posicionamentos do "outro", publicados no site do game, que podem argumentar, criticar, elogiar e refletir sobre 0 próprio lugar de fala ou perpectiva. Na postura 
crítica, não necessariamente depreciativa, como sujeitos significantes, são capazes de interagir, tensionar, descartar, aprender e levar para si 0 que lhe for necessário. Em The Sims e em seus diversos ambientes narratológicos, o que fica é não mais do que uma lúdica mas instigante possibilidade de jogar, experimentar, produzir, publicar, interagir e criar vínculos significativos com o "outro" e com o mundo.

\section{Referências}

ARDUINI, Juvenal. Ser multidimensional. In:

Destinação antropológica. São Paulo: Paulinas, 1989.

BENJAMIN, Walter. A obra de arte na era de sua reprodutibilidade técnica. In: Obras

escolhidas i: magia e técnica, arte e política. São Paulo: Brasiliense, 1996.

CHARAUDEAU, Patrick. Discursos das mídias. São Paulo: Contexto, 2006.

COUCHOT, Edmond. Da representação à simulação. In: PARENTE, André (org.). Imagem máquina: a era das tecnologias do virtual. Rio de Janeiro: 34, 1993.

COUTINHO, Pedro. Como jogar junto: narrativas em comunhão nos MUDs. 2007. Dissertação (Mestrado em Comunicação Social)- Programa de Pós-Graduação em Comunicação Social, Universidade Federal de Minas Gerais, Belo Horizonte, 2007.

LEAL, Bruno. Saber a narrativa. In: GUIMARÃES, C.; FRANÇA, V. (orgs.) Na mídia, na rua: narrativas do cotidiano. Belo Horizonte: Autêntica, 2006.

MURRAY, Janet. Hamlet no holodeck: o futuro da narrativa no ciberespaço. São Paulo: Itaú Cultural; Unesp, 2003.

WINKIN, Y. Bernard: a pragmática. In: MIÉGE, Bernard. 0 pensamento comunicacional. Petrópolis: Vozes, 2000.

\section{Sites:}

http://br.thesims3.com

http://chrisfried.blogspot.com

http://mynnasims.blogspot.com

http://www.thesims.ea.com

http://www.thesims2.br.ea.com

http://thesims3-chrisfried.blogspot.com 
The game of narratives: narratological chaining in the game The Sims

\section{Abstract:}

Having as theme "Games and Narratives", this article goes through a path, or better, a possible "narratological chaining" which, in a way, could give players of the game The Sims a possibility of expressing and approaching everyday life by means of different narrative forms. In this trajectory, the game, The Sims' official website narrative possibilities and the publishing of virtual journals of the game, which are written by the players' avatars' from the cyberquotidian. We tried to perceive, throughout the research, how players are able to express, experiment new forms of tensioning and being present in the world, by means of one of the several digital possibilities of narrative.

\section{Keywords:}

Communication and technology. Narratives. Digital games. Entertainment. The Sims.

\section{El juego de las narrativas: encadenamientos narratológicos del juego The Sims}

\section{Resumen:}

Con la temática "Games y Narrativas", este trabajo recurre un camino, o mejor, un posible "encadenamiento narratológico" que, de cierta forma, puede conceder a los jugadores del game The Sims, la posibilidad de se expresar y abordar el cotidiano por medio de diferentes formas narrativas. En ese trayecto, el game, las posibilidades narrativas del sitio oficial de The Sims, y las publicaciones de los "diarios" virtuales del game, que son escritos por los mismos jugadores a partir del cibercotidiano de sus avatares. Inentamos percibir, a lo largo de la investigación, cómo los jugadores logran expresarse, experimentar nuevas formas de tensionar y de hacerse presentes en el mundo, por medio de una de las diversas posibilidades digitales de narrativa.

\section{Palabras clave:}

Comunicación y tecnología. Narrativas. Juegos digitales. Entretenimiento. The Sims. 


\section{Expediente}

A revista E-Compós é a publicação científica em formato eletrônico da Associação Nacional dos Programas de Pós-Graduação em Comunicação (Compós). Lançada em 2004, tem como principal finalidade difundir a produção acadêmica de pesquisadores da área de Comunicação, inseridos em instituições do Brasil e do exterior.
E-COMPÓS I www.e-compos.org.br I E-ISSN 1808-2599

Revista da Associação Nacional dos Programas de Pós-Graduação em Comunicação. Brasília, v.13, n.2, maio/ago. 2010

A identificação das edições, a partir de 2008 passa a ser volume anual com três números.

\section{CONSELHO EDITORIAL}

Afonso Albuquerque

Universidade Federal Fluminense, Brasil

Alberto Carlos Augusto Klein

Universidade Estadual de Londrina, Brasi

Alex Fernando Teixeira Primo

Universidade Federal do Rio Grande do Sul, Brasil

Alfredo Vizeu

Universidade Federal de Pernambuco, Brasi

Ana Carolina Damboriarena Escosteguy

Pontifícia Universidade Católica do Rio Grande do Sul, Brasil

Ana Silvia Lopes Davi Médola

Universidade Estadual Paulista, Brasil

André Luiz Martins Lemos

Universidade Federal da Bahia, Brasil

Ângela Freire Prysthon

Universidade Federal de Pernambuco, Brasil

Antônio Fausto Neto

Universidade do Vale do Rio dos Sinos, Brasil

Antonio Carlos Hohlfeldt

Pontifícia Universidade Católica do Rio Grande do Sul, Brasil

Arlindo Ribeiro Machado

Universidade de São Paulo, Brasil

César Geraldo Guimarães

Universidade Federal de Minas Gerais, Brasil

Cristiane Freitas Gutfreind

Pontifícia Universidade Católica do Rio Grande do Sul, Brasil

Denilson Lopes

Universidade Federal do Rio de Janeiro, Brasil

Eduardo Peñuela Cañizal

Universidade Paulista, Brasi

Erick Felinto de Oliveira

Universidade do Estado do Rio de Janeiro, Brasil

Francisco Menezes Martins

Universidade Tuiuti do Paraná, Brasil

Gelson Santana

Universidade Anhembi/Morumbi, Brasil

Goiamérico Felício

Universidade Federal de Goiás, Brasil

Hector Ospina

Universidad de Manizales, Colômbia

Herom Vargas

Universidade Municipal de São Caetano do Sul, Brasil

leda Tucherman

Universidade Federal do Rio de Janeiro, Brasil

Itania Maria Mota Gomes

Universidade Federal da Bahia, Brasil

Janice Caiafa

Universidade Federal do Rio de Janeiro, Brasil

Jeder Silveira Janotti Junior

Universidade Federal da Bahia, Brasil

João Freire Filho

Universidade Federal do Rio de Janeiro, Brasil

John DH Downing

University of Texas at Austin, Estados Unidos

José Luiz Aidar Prado

Pontifícia Universidade Católica de São Paulo, Brasil

José Luiz Warren Jardim Gomes Braga

Universidade do Vale do Rio dos Sinos, Brasil

Juremir Machado da Silva

Pontifícia Universidade Católica do Rio Grande do Sul, Brasil

Lorraine Leu

University of Bristol, Grã-Bretanha

Luiz Claudio Martino

Universidade de Brasília, Brasil

Maria Immacolata Vassallo de Lopes

Universidade de São Paulo, Brasil

Maria Lucia Santaella

Pontifícia Universidade Católica de São Paulo, Brasil

Mauro Pereira Porto

Tulane University, Estados Unidos

Muniz Sodre de Araujo Cabral

Universidade Federal do Rio de Janeiro, Brasil

Nilda Aparecida Jacks

Universidade Federal do Rio Grande do Sul, Brasil

Paulo Roberto Gibaldi Vaz

Universidade Federal do Rio de Janeiro, Brasil

Renato Cordeiro Gomes

Pontifícia Universidade Católica do Rio de Janeiro, Brasil

Ronaldo George Helal

Universidade do Estado do Rio de Janeiro, Brasil

Rosana de Lima Soares

Universidade de São Paulo, Brasil

Rossana Reguillo

Instituto Tecnológico y de Estudios Superiores do Occidente, México

Rousiley Celi Moreira Maia

Universidade Federal de Minas Gerais, Brasil

Samuel Paiva

Universidade Federal de São Carlos, Brasil

Sebastião Albano

Universidade Federal do Rio Grande do Norte, Brasil

Sebastião Carlos de Morais Squirra

Universidade Metodista de São Paulo, Brasil

Simone Maria Andrade Pereira de Sá

Universidade Federal Fluminense, Brasil

Suzete Venturelli

Universidade de Brasília, Brasil

Valério Cruz Brittos

Universidade do Vale do Rio dos Sinos, Brasil

Veneza Mayora Ronsini

Universidade Federal de Santa Maria, Brasil

Vera Regina Veiga França

Universidade Federal de Minas Gerais, Brasi

COMISSÃO EDITORIAL

Felipe da Costa Trotta I Universidade Federal de Pernambuco, Brasi Rose Melo Rocha I Escola Superior de Propaganda e Marketing, Brasil Adriana Braga I Pontifícia Universidade Católica do Rio de Janeiro, Brasil

CONSULTORES AD HOC

Roseli Figaro I Universidade de São Paulo, Brasil

Miguel Serpa Pereira I Pontifícia Universidade Católica do Rio de Janeiro, Brasi João Maia I Universidade do Estado do Rio de Janeiro, Brasil Paulo Cunha Filho I Universidade Federal de Pernambuco, Brasi

Benjamim Picado I Universidade Federal Fluminense, Bras Josimey Silva I Universidade Federal do Rio Grande do Norte, Brasil

EDIÇÃO DE TEXTO E RESUMOS I Everton Cardoso

TRADUÇÕES PARA 0 INGLÊS I Lisa Earl Castillo e Sabrina Gledhil EDITORAÇ̃̃o ELETRÔNICA I Roka Estúdio
COMPOS I wWw.compos.org.br

Associação Nacional dos Programas de Pós-Graduação em Comunicação

Presidente

Itania Maria Mota Gomes

Universidade Federal da Bahia, Brasil

itania@ufba.br

Vice-presidente

Julio Pinto

Pontifícia Universidade Católica de Minas Gerais, Brasil juliopinto@pucminas.br

Secretária-Geral

Ana Carolina Escosteguy

Pontifícia Universidade Católica do Rio Grande do Sul, Brasil carolad@pucrs.br 